\title{
30-day readmission after radical cystectomy: Identifying targets for improvement using the phases of surgical care
}

Ian Berger, BS ${ }^{1,2}$; Leilei Xia, $\mathrm{MD}^{3}$; Christopher Wirtalla, $\mathrm{BA}^{2}$; Phillip Dowzicky, $\mathrm{MD}^{2,4}$; Thomas J. Guzzo, MD, MPH ${ }^{3}$; Rachel R. Kelz, MD, MSCE ${ }^{2,4}$

${ }^{1}$ University of Pennsylvania Perelman School of Medicine, Philadelphia, PA, United States; ${ }^{2}$ Center for Surgery and Health Economics, Department of Surgery, University of Pennsylvania Perelman School of Medicine, Philadelphia, PA, United States; ${ }^{3}$ Division of Urology, Department of Surgery, University of Pennsylvania Perelman School of Medicine, Philadelphia, PA, United States; ${ }^{4}$ Department of Surgery, University of Pennsylvania Perelman School of Medicine, Philadelphia, PA, United States

Acknowledgement: The American College of Surgeons National Surgical Quality Improvement Program and the hospitals participating in the ACS NSQIP are the source of the data used herein; they have not verified and are not responsible for the statistical validity of the data analysis or the conclusions derived by the author

Cite as: Can Urol Assoc J 2018 November 20; Epub ahead of print. http://dx.doi.org/10.5489/cuaj.5455

Published online November 20, 2018

$* * *$

\section{Abstract}

Introduction: Postoperative readmissions following radical cystectomy (RC) have gained attention in the past decade. Postoperative and post-discharge complications play a role in readmission rates; however, our ability to predict readmissions remains poor.

Methods: Using the National Surgical Quality Improvement Program database, we identified patients with bladder cancer undergoing RC from 2013-2015. Complications were defined as postoperative and post-discharge. Outcomes were 30-day readmission, post-discharge complications, and post-discharge major complications. Patient, operative, and complication factors were assessed using multivariable logistic regression.

Results: We identified 4457 patients who underwent RC; $9.2 \%$ of patients experienced a postoperative complication, $18.8 \%$ experienced a post-discharge complication, and 20.3\% were readmitted. Overweight and obese body mass index (BMI), dependent functional status, chronic obstructive pulmonary disease (COPD), a continent diversion, and duration of operation were associated with post-discharge complications. Postoperative complications were not associated with post-discharge complications. Readmission was associated with Black race (odds ratio [OR] 1.5; 95\% confidence interval [CI] 1.0-2.1), overweight (OR 1.5; 95\% CI 1.2-1.8) and obese BMI (OR 1.5; 95\% CI 1.2-1.9), diabetes (OR 1.2; 95\% CI 1.0-1.5), COPD (OR 1.4; 95\% 
CI 1.0-1.8), steroid use (OR 1.5; 95\% CI 1.0-2.2), a continent diversion (OR 1.4; 95\% CI 1.11.7), duration of operation (OR 1.1; 95\% CI 1.1-1.2), and postoperative complications (OR 1.5; 95\% CI 1.2-2.0). The majority of readmissions experienced a post-discharge complication. Conclusions: Factors that span the preoperative, intraoperative, postoperative, and postdischarge phases of care were identified to increase readmission risk. To improve readmission rates, interventions will have to target factors across the surgical experience.

\section{Introduction}

Over the last decade, hospital readmissions have been increasingly viewed as a major driver of financial burden in the healthcare system. In the U.S., readmission rates are publically tracked and hospitals are penalized for high readmission rates for certain medical conditions and surgical procedures. The urgency of addressing the readmission problem extends beyond national healthcare spending to the protection of the public, as patients who are readmitted experience significantly higher morbidity. ${ }^{1-3}$

Radical cystectomy $(\mathrm{RC})$ remains a particularly morbid operation with approximately one in four patients being readmitted within 30 days of discharge. ${ }^{4}$ These readmissions result in higher patient mortality as well as significantly increased costs. ${ }^{5}$ Little progress has been made in reducing this rate over the last decade, which has primarily been attributed to non-modifiable patient and operative factors. ${ }^{6-8}$ Recently, the post-discharge period has become a focus of investigation and intervention. ${ }^{9,10}$ Post-discharge complications are known to increase the risk of readmission in surgical populations. There is an increasing effort to catch them early in the outpatient setting before they lead to readmission. ${ }^{11}$

Of particular importance to future interventions is identification of patients at high risk for post-discharge complications and readmission. Our study used the American College of Surgeons National Quality Improvement Program (ACS NSQIP) database to explore the effect of pre-operative, peri-operative, and post-operative factors on post-discharge complications and readmissions in order to target quality improvement interventions.

\section{Methods}

The ACS NSQIP Participant Use File (PUF) captures cases from submitting hospitals in datasets that de-identify patients, hospitals, and caregivers. ${ }^{12}$ The 2015 dataset contains information on 30-day morbidity and mortality from 603 submitting hospitals. Data is captured from both the inpatient and outpatient settings. Using the ACS NSQIP PUF, 6,400 patients undergoing RC from 2013 to 2015 were identified using Common Procedural Terminology (CPT) codes for RC (51570, 51575, 51580, 51585, 51590, 51595, 51596, and 51597). Patients were included if they were $\geq 18$ years old and had an ICD-9 or ICD-10 diagnosis code of bladder malignancy (188.x, 233.7, 239.4, C67.x, D09.0, D49.4).

Cohort selection is shown in Figure 1. Patients with the following characteristics were excluded from the study: had disseminated cancer $(n=331)$, transferred from another acute care 
hospital or urgent/emergent operation status $(n=669)$ or were hospitalized prior to the operation $(n=175)$. Patients were also excluded if they had a duration of operation less than 120 minutes $(n=20)$ or a length of stay (LOS) of 2 days or less $(n=11)$ and did not expire in the hospital. These likely represented aborted or aberrantly coded procedure as the median operative time for $\mathrm{RC}$ has been reported around 400 minutes, while average LOS is 7 days. ${ }^{13,14}$ Patients were excluded if they had key missing data $(n=15)$. A sub-group analysis was performed which excluded patients with a LOS $>14$ days $(n=722)$. NSQIP only tracks outcomes for 30 days from the day of the operation, and thus patients with extended LOS have a shorter post-discharge follow up time. Thus, results from the sub-group analysis were used to draw primary conclusions rather than the overall study cohort.

The primary outcome of the study was all-cause, 30-day readmission. The secondary outcomes were any post-discharge complications and major post-discharge complications. Complications were defined as the following: wound (superficial surgical site infection, deep incisional surgical site infection, organ space infection, wound disruption), sepsis (sepsis and septic shock), renal (acute renal failure and progressive renal insufficiency), venous thromboembolism (VTE) (pulmonary embolism and deep venous thrombosis), respiratory (pneumonia, unplanned reintubation, ventilation for $>48$ hours), stroke, urinary tract infection (UTI), cardiac (cardiac arrest requiring CPR and myocardial infarction), reoperation and death. Minor complications were defined as superficial and deep SSI, wound dehiscence, renal insufficiency, and UTI. ${ }^{15}$ All other complications were defined as major complications. Complications were tracked from the day of the operation to the day of the reported complication. Patients that did not have their date of complication recorded were excluded from the timing analysis. The American College of Surgeons has published a new taxonomy to describe the phases of surgical care in order to facilitate the advancement of surgical quality and safety (Figure 2). ${ }^{16}$ We applied this taxonomy to identify opportunities for improvement. Postoperative complications were defined as taking place before or on the day of discharge while post-discharge complications were defined as those thereafter and until 30 days after the operation.

Data on patient characteristics was collected and included sex, age, race, functional status, body mass index (underweight $<18.5 \mathrm{~kg} / \mathrm{m}^{2}$, normal $18.5-24.9 \mathrm{~kg} / \mathrm{m}^{2}$, overweight $25-29.9$ $\mathrm{kg} / \mathrm{m}^{2}$, obese $\geq 30 \mathrm{~kg} / \mathrm{m}^{2}$ ), American Society of Anesthesiologists (ASA) classification, hypertension requiring medication, smoking status within a year of surgery, diabetes requiring medication, dyspnea at rest, steroid use for a chronic condition at time of surgery, history of severe chronic obstructive pulmonary disease (COPD), weight loss ( $>10 \%$ of body weight in 6 months before the operation), congestive heart failure (CHF) within 30 days of surgery, preoperative sepsis within 48 hours of surgery, and pre-operative transfusion within 72 hours of surgery. Operations were classified by CPT codes and stratified into continent (51596) versus non-continent (51570, 51575, 51580, 51585, 51590, 51595, 51597) operations. 
Using the data obtained from the CPT codes, descriptive statistics were calculated. Univariate analysis was used to analyze the effect of post-discharge complications on readmission. Mutivariable models using pre- and peri-operative characteristics were used to assess each factor's effect on readmission, post-discharge complication, and post-discharge major complication risk. Covariates for these models included age, sex, race, BMI, ASA score, functional status, smoking status, individual patient comorbidities, pre-operative sepsis, preoperative transfusion, continent versus non-continent urinary diversion, duration of operation in hours, wound class, length of stay, and the presence of any post-operative complication. Patients who died before discharge $(n=29)$ were excluded from the multivariable models as they could not contribute to post-discharge adverse events. All analysis was done with STATA 15.1 statistical software (STATA Corp, College Station, TX) and tests used $\mathrm{p}<0.05$ to determine significance. The study was deemed exempt from review by the University of Pennsylvania institutional review board (protocol 828694).

\section{Results}

Patient population

We identified 5,173 patients who underwent RC between 2013 and 2015. After excluding patients with LOS>14 days, 4,457 patients remained in the sub-group analysis. Major characteristics of patients stratified by those readmitted and those not readmitted are shown in Table 1 for the subgroup analysis. Full patient characteristics are shown in Supplementary Table 1 and Supplementary Table 2 for sub-group and overall cohorts, respectively. For the sub-group analysis, the mean age of included patients was 68.3 (standard deviation (SD), 10.2), with the majority being male (76.8\%) and Caucasian (84.1\%). Other common comorbidities included hypertension (59.7\%), smoking (24.2\%), and diabetes (19.5\%). Cystectomy with ureteroileal conduit (68.1\%) was the most common procedure and $83.2 \%$ of patients underwent a noncontinent procedure. Patients remained in the hospital for a mean of 7.3 days (SD 2.2 days) after the operation. Additionally, 26.2\% of patients experienced one or more complication, with 9.2\% of patients experiencing a complication post-operatively and $18.8 \%$ experiencing a complication post-discharge. The overall rate of readmission within 30 days of the operation was $20.3 \%$.

Factors associated with readmission and post-discharge complications

Using univariable analysis, post-discharge complications were significantly associated with readmission (OR, 21.4; 95\% CI, 17.8-25.7; p<0.001). Multivariable analysis was performed in the sub-group and overall cohort for patient factors associated with readmission, post-discharge complications, and post-discharge major complications (Supplementary Tables 3 and 4). Significant factors for the sub-group analysis are shown in Table 2.

\section{Characterizations of complications}

Post-surgical complications and their association with readmission are displayed in Table 3 for the sub-group analysis and Supplementary Table 5 for the overall cohort. In the sub-group, major 
complications comprised $52.8 \%$ of all complications. The most common complications were infectious in nature with wound (27.3\%), UTI's (22.0\%), and sepsis or septic shock (21.6\%) making up the majority of all complications. All post-operative complications that occurred in 10 or more patients had associated readmission rates less than $50 \%$. All individual post-discharge complication categories had readmission rates greater than $60 \%$ with the exception of patient death (35.0\%). Similar to the overall complications, the most common post-discharge complications were wound (28.6\%), UTI's (26.2\%), and sepsis (25.8\%). Of the patients who were readmitted, $63.3 \%$ experience a post-discharge complication with $79.9 \%$ of those complications being major.

Multiple complications occurred in $24.7 \%$ of patients who experienced a complication before discharge. Meanwhile, multiple complications occurred in $43.0 \%$ of the patients who had a complication after discharge. Of the patients that had a post-operative complication, 19.3\% went on to develop a post-discharge complication. Sepsis and UTI's were the most common post-discharge complications that were associated with other complications. Additionally, of the patients who developed a post-discharge UTI, 46.4\% also developed sepsis.

Timing of post-discharge complications and readmission

Given their strong association with readmissions, the timing of post-discharge complications was further investigated in the sub-group analysis. Patients experienced the first complication a median of 13 days after the operation (interquartile range (IQR) 7-19 days) and 9 days after discharge (IQR 5-14 days). Median time to readmission occurred 15 days after the operation (IQR 11-21 days) and 7 days (IQR 4-13 days) after discharge. Figure 3 shows the timing of complications and readmissions from day of discharge.

\section{Discussion}

Our sub-group analysis identified 4,457 patients who had undergone RC in a 3 year period using the ACS NSQIP database. We found that more than a quarter of the patients experienced a postoperative or post-discharge complication and twenty percent required a readmission. Postoperative complications were not associated with post-discharge complications. Infections were the most common complication requiring readmission. Pre-operative (BMI, diabetes, COPD and steroid use), intra-operative (operative duration), post-operative (complications), and postdischarge (complications) factors were associated with the likelihood of readmission. Based on the study results, actionable targets for improvement may exist in the pre-operative and postdischarge phases.

Readmission rates in prior studies range from 19.7-28.5\%, which is consistent with our rate of $20.3 \% .{ }^{17-20}$ We found multiple patient comorbidities that predicted readmission. Previous papers have used composite comorbidity or frailty scores in risk adjustment. ${ }^{6,15,21}$ This is the first study to demonstrate the important association of each independent risk factors with readmissions in the cystectomy population. Given the different medical and social factors surrounding each individual comorbidity, we hypothesized that some might contribute to 
readmission risk more than others. In so doing, we identified increasing BMI, diabetes, COPD, and steroid use as independent predictors of readmission, providing evidence that optimizing pre-surgical management of these conditions may reduce risk. Elements of the American College of Surgeons Strong for Surgery campaign may be useful in the mitigation of several of these risk factors. $^{22}$ The campaign's physician toolkit specifically targets pre-operative nutritional status, smoking cessation, glycemic control, and medication use through standardization of preoperative risk assessment and patient engagement. Based on our results, interventions such as identifying and beginning treatment in patients with undiagnosed diabetes and tapering steroid doses may lead to decreased readmission rates. However, time to cystectomy must not be delayed in order to preserve oncologic outcomes.

Each of the identified risk factors is known to impair immunity and increase the odds of infections. ${ }^{23-25}$ As infectious complications were most common among readmissions, improved management of these risk factors and peri-operative infection control would likely reduce the occurrence rate. Antimicrobial prophylaxis and good surgical technique should always be followed peri-operatively, however protocols for prophylaxis after RC remain under debate. Recently, Pariser et al. ${ }^{26}$ modified the protocol at their institution using existing culture data. They found that broadening antimicrobial coverage from cefoxitin to ampicillin-sulbactam, gentamicin, and fluconazole decreased their infection rate by $11 \%$. Targeting prophylaxis based on previous data provides one avenue where institutions may decrease their infection rates while minimizing the risk of exposing patients to drug resistant organisms. A recent study of the NSQIP database found that women are at increased risk of SSI following RC. ${ }^{27}$ Our multivariable analysis controlled for sex, and thus we believe our outcomes are applicable to women. However, we did not stratify post-discharge complications by category, which explains the differences in our results.

Post-discharge home services, which have been shown to reduce readmission rates in some settings, may be useful in this population as well. ${ }^{28,29}$ Innovative programs may prove to be beneficial in these high risk surgical patients. Specifically, the "discharge to assess" program has shown promise in elderly populations and could be transitioned to other populations. ${ }^{30}$ This program has moved the formal discharge to the patient's home, after the transition out of the hospital, in order to assess the needs in the patient's own home and ensure a viable discharge plan is actualized. Close follow-up is also warranted in this population. With a mathematical model, Krishnan et al. ${ }^{9}$ demonstrated that an office visit at day 4 or 5 post-discharge has the greatest chance at preventing readmission. However, they used fixed probability for detecting complications by office visit or telephone and there has not been a published series implementing early office visits for RC.

Risk scores to predict readmission might be of use to identify patients that require increased or altered post-discharge care. The only risk score that exists for adverse events after RC is the ACS NSQIP risk calculator, which was created based on aggregate NSQIP data across all surgical procedures. ${ }^{31}$ However, it commonly under-predicts outcomes after RC. ${ }^{32}$ Studies 
have suggested that patient characteristics do not predict readmission in a reliable fashion, and prospective studies would require large sample sizes to create and validate such tools. ${ }^{17,19,33}$ Using the results of our multivariable analysis, we attempted to build and validate a nomogram and risk score for readmission. However, we also found that using patient and operative characteristics led to poor prediction of readmission. It is likely that variables not captured in NSQIP, such as prior abdominal surgery, radiation, chemotherapy, socio-economic status, and distance to index hospital need to be included to accurately predict readmission risk.

Our study demonstrates patterns of care that are consistent with other studies. Similar to our findings, Sood et al. found that patients with post-operative complications have an increased risk of readmission. ${ }^{14}$ Our study builds on this evidence using a larger patient cohort and examining the association between post-operative and post-discharge complications as a potential explanation for readmissions. This allowed us to test, and subsequently find no association, between post-operative complications and post-discharge complications. Our study adds to the existing literature on readmissions in defining the distinction between post-operative and post-discharge complications. It identifies factors to serve as targets for quality improvement and matches these factors to the phases of care and programs that exist in order to encourage readers to address these issues in the local care setting. Strategies to prevent readmission should then be shared with the urological community, as published series describing methods to reduce readmission after RC are currently lacking in the literature.

There are several limitations to our study. ACS-NSQIP only collects data from participating institutions, and thus may miss some cystectomies performed in this time period. Differences between institutions that participate in data collection and those that don't might influence our results. NSQIP is de-identified at the patient, surgeon, and hospital level.

Therefore, we cannot account for factors such as surgeon experience and hospital volume which may have an effect on results such as complication rate. While patient comorbidities were noted to increase the risk of readmission, it is unclear the pre-operative severity of these comorbidities, or how many of these patients had optimized medical management of their conditions prior to surgery. Certain factors such as neoadjuvant chemotherapy, use of laparoscopic or roboticassistance, and other outcomes, such as anastomotic leak, are not collected and are often of interest when examining cystectomy populations. Because outcomes are only collected 30 days after the operation, patients with longer LOS have fewer days to present with post-discharge complications and be captured by the database. We attempted to minimize this bias by excluding patients with lengths of stay greater than 14 days in the sub-group analysis. However, doing so likely underestimates the incidence of adverse events in this population. Thus, we included an analysis of the full cohort in the supplementary section. Our study specifically examined early complications following RC. Thus, we likely underestimated the total amount of adverse events that occur after RC with extended post-operative follow-up. While complications were stratified by major and minor, NSQIP does not collect information on Clavien-Dindo grade. 
Complications within each category may be heterogeneous. Additionally, the median time to complication was shorter than the median time to readmission in our study. Caution must be used when interpreting the timing of adverse events in NSQIP. Complications may only be identified and recorded on readmission, even if they had occurred sooner. Finally, factors such as tumor stage, socioeconomic status, insurance status, and distance to index hospital are not collected by ACS-NSQIP and have been shown to affect readmission rates. ${ }^{5}$

\section{Conclusion}

Over $20 \%$ patients are readmitted following RC. Risk is influenced by factors that span the surgical experience. Opportunity exist to improve readmission rates, however interventions must collectively target the pre-operative, intra-operative, post-operative, and post-discharge phases of care. Multi-faceted approaches may reduce the burden of readmissions in this population. 


\section{References}

1. Kohlnhofer, B. M., Tevis, S. E., Weber, S. M. et al. Multiple complications and short length of stay are associated with postoperative readmissions. Am J Surg 2014; 207: 449.

2. Tsai, T. C., Joynt, K. E., Orav, E. J. et al. Variation in surgical-readmission rates and quality of hospital care. $N$ Engl J Med 2013; 369: 1134.

3. Lawson, E. H., Hall, B. L., Louie, R. et al. Association between occurrence of a postoperative complication and readmission: implications for quality improvement and cost savings. Ann Surg 2013; 258: 10.

4. Skolarus, T. A., Jacobs, B. L., Schroeck, F. R. et al. Understanding hospital readmission intensity after radical cystectomy. J Urol 2015; 193: 1500.

5. Stitzenberg, K. B., Chang, Y., Smith, A. B. et al. Exploring the burden of inpatient readmissions after major cancer surgery. J Clin Oncol 2015; 33: 455.

6. Minnillo, B. J., Maurice, M. J., Schiltz, N. et al. Few modifiable factors predict readmission following radical cystectomy. Can Urol Assoc J 2015; 9: E439.

7. James, A. C., Izard, J. P., Holt, S. K. et al. Root Causes and Modifiability of 30-Day Hospital Readmissions after Radical Cystectomy for Bladder Cancer. J Urol 2016; 195: 894.

8. Jacobs, B. L., Zhang, Y., Tan, H. J. et al. Hospitalization trends after prostate and bladder surgery: implications of potential payment reforms. J Urol 2013; 189: 59.

9. Krishnan, N., Liu, X., Lavieri, M. S. et al. A Model to Optimize Followup Care and Reduce Hospital Readmissions after Radical Cystectomy. J Urol 2016; 195: 1362.

10. Krishnan, N., Li, B., Jacobs, B. L. et al. The Fate of Radical Cystectomy Patients after Hospital Discharge: Understanding the Black Box of the Pre-readmission Interval. Eur Urol Focus 2016.

11. Glance, L. G., Kellermann, A. L., Osler, T. M. et al. Hospital readmission after noncardiac surgery: the role of major complications. JAMA Surg 2014; 149: 439.

12. American College of Surgeons National Quality Surgical Improvement Program. User Guide for the 2015 Participant Use File. https://www.facs.org/ /media/files/quality \%20programs/nsqip/nsqip_puf_user_guide_2015.ashx. Accessed March 3, 2018.

13. Filson, C. P., Tan, H. J., Chamie, K. et al. Determinants of radical cystectomy operative time. Urol Oncol 2016; 34: 431.e17.

14. Sood, A., Kachroo, N., Abdollah, F. et al. An Evaluation of the Timing of Surgical Complications Following Radical Cystectomy: Data From the American College of Surgeons National Surgical Quality Improvement Program. Urology 2017; 103: 91.

15. Xia, L., Taylor, B. L., Newton, A. D. et al. Early discharge and post-discharge outcomes in patients undergoing radical cystectomy for bladder cancer. BJU Int 2017.

16. Ko, D. H. a. C.: Optimal Resources for Surgical Quality and Safety: American College of Surgeons, 2017.

17. Stimson, C. J., Chang, S. S., Barocas, D. A. et al. Early and late perioperative outcomes following radical cystectomy: 90-day readmissions, morbidity and mortality in a contemporary series. J Urol 2010; 184: 1296.

18. Hu, M., Jacobs, B. L., Montgomery, J. S. et al. Sharpening the focus on causes and timing of readmission after radical cystectomy for bladder cancer. Cancer 2014; 120: 1409. 
19. Leow, J. J., Gandaglia, G., Sood, A. et al. Readmissions after major urologic cancer surgery. Can J Urol 2014; 21: 7537.

20. Pak, J. S., Lascano, D., Kabat, D. H. et al. Patterns of care for readmission after radical cystectomy in New York State and the effect of care fragmentation. Urol Oncol 2015; 33: 426.e13.

21. Lorentz, C. A., Gilbert, K., Alemozaffar, M. et al. Risk of Readmission After Uncomplicated Hospitalization After Radical Cystectomy. Clin Genitourin Cancer 2018.

22. American College of Surgeons. Strong for Surgery. https://www.facs.org/quality programs/strong-for-surgery. Accessed April 4, 2018.

23. Lazar, H. L. How important is glycemic control during coronary artery bypass? Adv Surg 2012; 46: 219.

24. Isik, O., Kaya, E., Sarkut, P. et al. Factors Affecting Surgical Site Infection Rates in Hepatobiliary Surgery. Surg Infect (Larchmt) 2015; 16: 281.

25. Dhurandhar, N. V., Bailey, D., Thomas, D. Interaction of obesity and infections. Obes Rev 2015; 16: 1017.

26. Pariser, J. J., Anderson, B. B., Pearce, S. M. et al. The effect of broader, directed antimicrobial prophylaxis including fungal coverage on perioperative infectious complications after radical cystectomy. Urol Oncol 2016; 34: 121.e9.

27. Abdi, H., Elzayat, E., Cagiannos, I. et al. Female radical cystectomy patients have a higher risk of surgical site infections. Urol Oncol 2018.

28. Tevis, S. E., Weber, S. M., Kent, K. C. et al. Nomogram to Predict Postoperative Readmission in Patients Who Undergo General Surgery. JAMA Surg 2015; 150: 505.

29. Naylor, M. D., Brooten, D., Campbell, R. et al. Comprehensive discharge planning and home follow-up of hospitalized elders: a randomized clinical trial. Jama 1999; 281: 613.

30. Institute for Healthcare Improvement. Discharge to Assess: "Flipping” Discharge Assessment from Hospital to Home. http://www.ihi.org/resources/Pages/ Publications/Discharge-to-Assess-Flipped-Discharge- Innovation-Case-Study.aspx. Accessed April 4, 2018.

31. Bilimoria, K. Y., Liu, Y., Paruch, J. L. et al. Development and evaluation of the universal ACS NSQIP surgical risk calculator: a decision aid and informed consent tool for patients and surgeons. J Am Coll Surg 2013; 217: 833.

32. Golan, S., Adamsky, M. A., Johnson, S. C. et al. National Surgical Quality Improvement Program surgical risk calculator poorly predicts complications in patients undergoing radical cystectomy with urinary diversion. Urol Oncol 2018; 36: 77.e1.

33. Baack Kukreja, J., Kamat, A. M. Strategies to minimize readmission rates following major urologic surgery. Ther Adv Urol 2017; 9: 111. 


\section{Figures and Tables}

Fig. 1. Cohort selection for the subgroup analysis. ASA: American Society of Anesthesiologists; CPT: common procedural terminology; LOS: length of stay; RC: radical cystectomy.

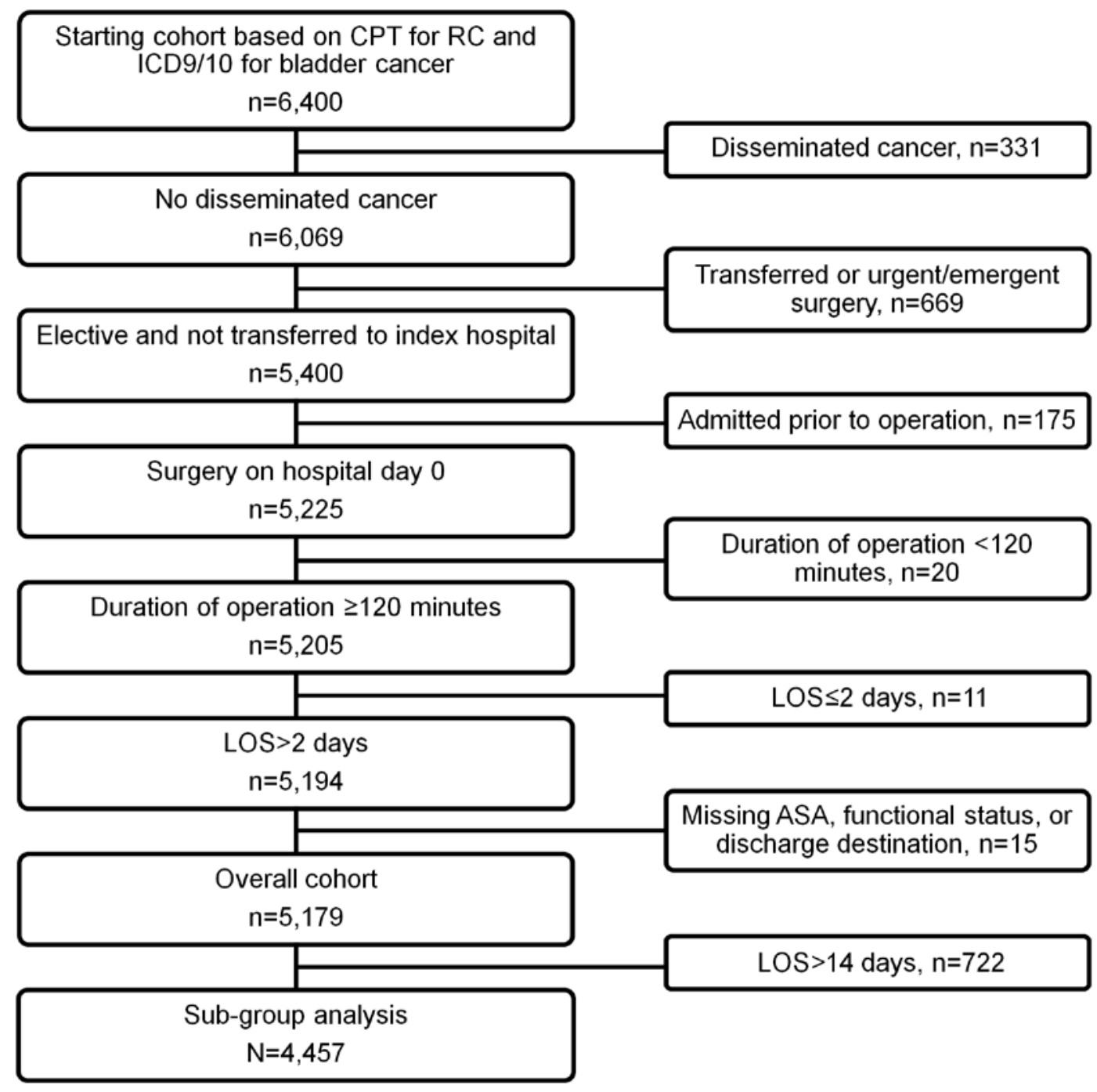


Fig. 2. American College of Surgeons surgical stages of care. ${ }^{16}$

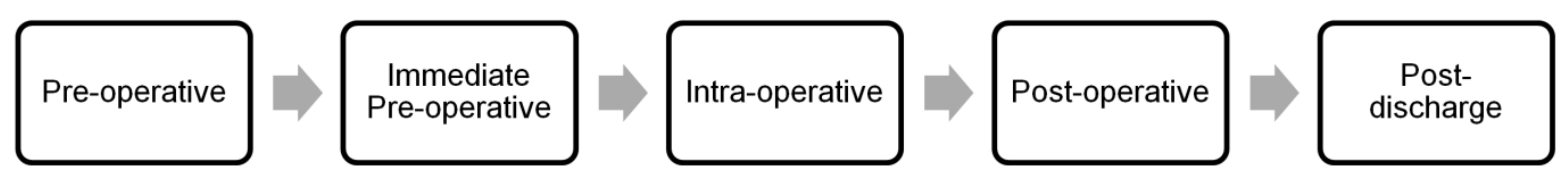

Fig. 3. Timing of (a) complications, and (b) readmissions measured from the day of discharge for the subgroup analysis. Dashed lines represent 7, 14, and 21 days post-discharge.
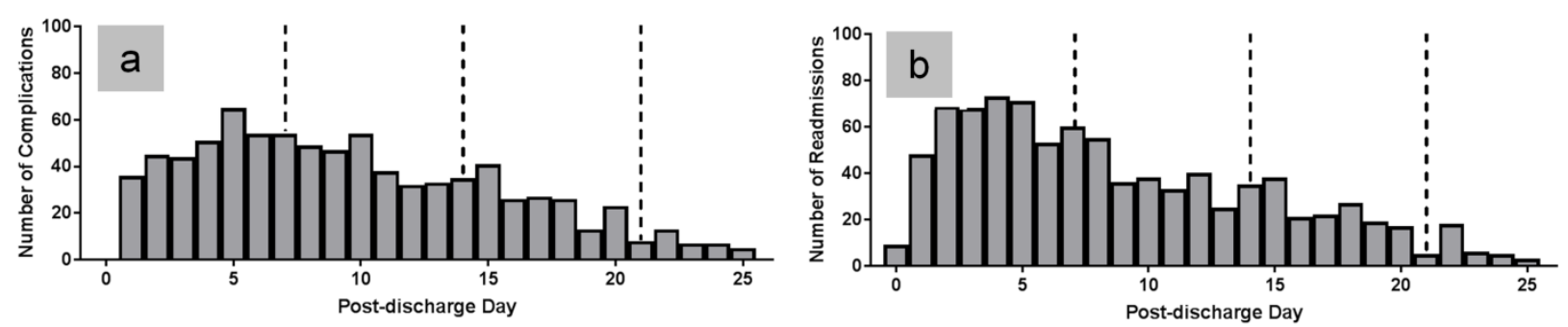


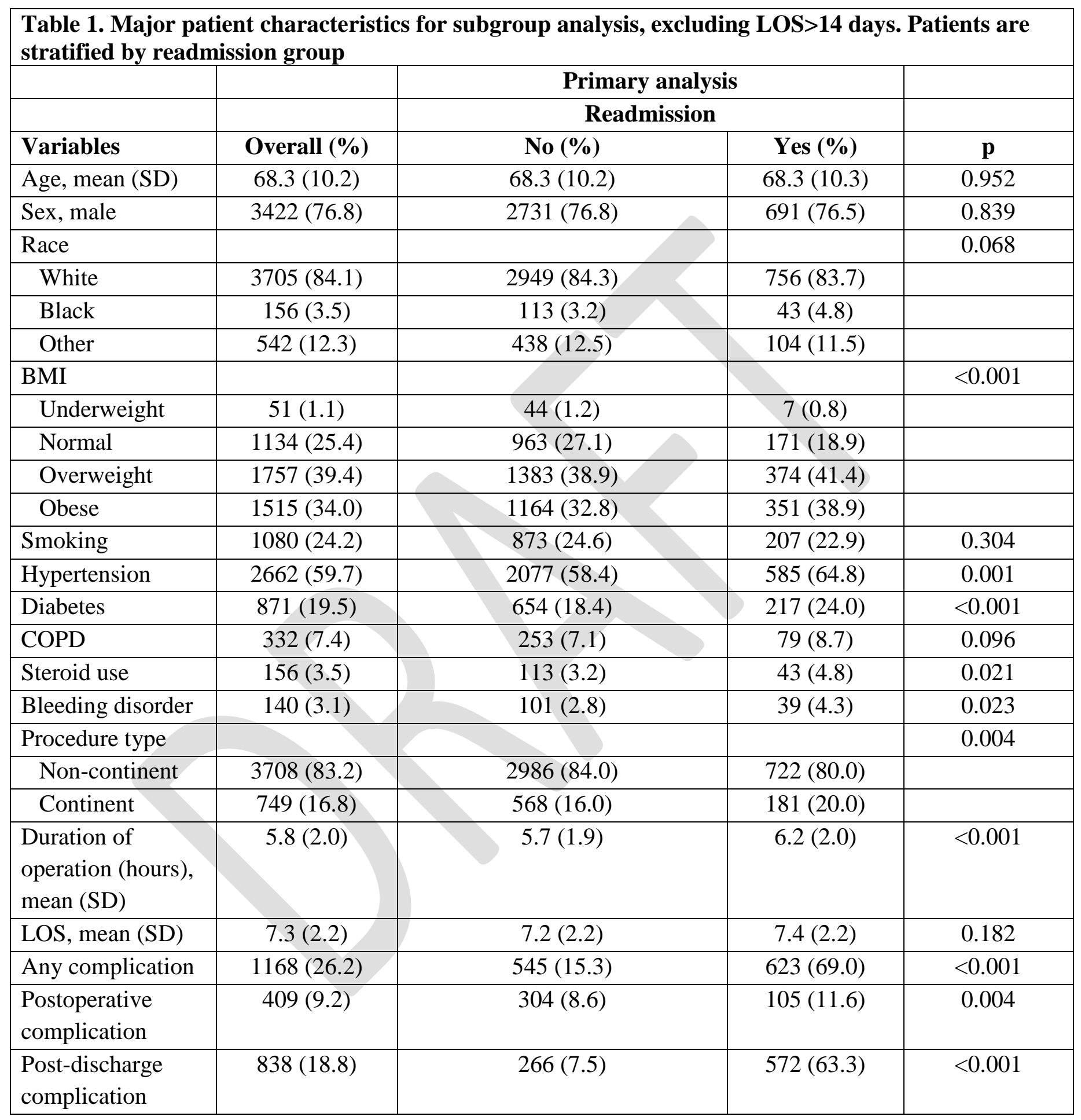

BMI: body mass index; COPD: chronic obstructive pulmonary disease; LOS: length of stay; SD: standard deviation. 


\begin{tabular}{|c|c|c|c|c|c|c|}
\hline & $\begin{array}{l}\text { Post-discharge } \\
\text { complications }\end{array}$ & & $\begin{array}{l}\text { Post-discharge } \\
\text { complications }\end{array}$ & jor & Readmission & \\
\hline Covariates & OR (95\% CI) & $\mathbf{p}$ & OR (95\% CI) & $\mathbf{p}$ & OR (95\% CI) & $\mathbf{p}$ \\
\hline Black race & - & - & - & - & $1.5(1.0-2.1)$ & 0.044 \\
\hline Overweight BMI & $1.4(1.1,1.7)$ & 0.003 & ( & - & $1.5(1.2,1.8)$ & $<0.001$ \\
\hline Obese BMI & $1.7(1.4,2.2)$ & $<0.001$ & $1.6(1.2,2.1)$ & $<0.001$ & $1.5(1.2,1.9)$ & $<0.001$ \\
\hline $\begin{array}{l}\text { Dependent } \\
\text { functional status }\end{array}$ & $2.1(1.0-: 4.1)$ & 0.042 & - & - & - & - \\
\hline Hypertension & - & - & $1.3(1.0-1.6)$ & 0.021 & - & - \\
\hline Diabetes & - & - & - & - & $1.2(1.0,1.5)$ & 0.030 \\
\hline COPD & $1.4(1.0,1.9)$ & 0.030 & - & - & $1.4(1.0,1.8)$ & 0.041 \\
\hline Steroid use & - & - & 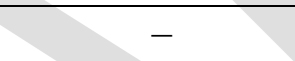 & - & $1.5(1.0-2.2)$ & 0.034 \\
\hline $\begin{array}{l}\text { Continent } \\
\text { diversion }\end{array}$ & $1.5(1.2-1.8)$ & $<0.001$ & $1.5(1.2-1.9)$ & 0.002 & $1.4(1.1-1.7)$ & 0.004 \\
\hline $\begin{array}{l}\text { Duration of } \\
\text { operation }\end{array}$ & $1.1(1.1,1.2)$ & $<0.001$ & $1.1(1.1,1.2)$ & $<0.001$ & $1.1(1.1-1.2)$ & $<0.001$ \\
\hline $\begin{array}{l}\text { Postoperative } \\
\text { complications }\end{array}$ & & - & - & - & $1.5(1.2-2.0)$ & 0.001 \\
\hline
\end{tabular}

-: non-significant factors. BMI: body mass index; CI: confidence interval; COPD: chronic obstructive pulmonary disease; LOS: length of stay; OR: odds ratio. 
Table 3. Timing of specific postoperative complications and their associated readmission rates

\begin{tabular}{|l|c|c|c|c|c|}
\hline Complication type & $\begin{array}{c}\text { Overall } \\
\mathbf{( \% )}\end{array}$ & $\begin{array}{c}\text { Number } \\
\text { occurring } \\
\text { postoperative, n } \\
\mathbf{( \% )}\end{array}$ & $\begin{array}{c}\text { Readmission } \\
\text { rate when } \\
\text { postoperative }\end{array}$ & $\begin{array}{c}\text { Number } \\
\text { occurring post- } \\
\text { discharge, n (\%) }\end{array}$ & $\begin{array}{c}\text { Readmission } \\
\text { rate when post- } \\
\text { discharge }\end{array}$ \\
\hline Major complications & $791(17.8)$ & $251(5.6)$ & 21.5 & $572(12.8)$ & 79.9 \\
\hline Minor complications & $707(15.9)$ & $202(4.5)$ & 28.7 & $529(11.9)$ & 63.5 \\
\hline Wound & $474(10.6)$ & $140(3.1)$ & 35.0 & $353(7.9)$ & 62.9 \\
\hline Sepsis & $374(8.4)$ & $56(1.3)$ & 7.1 & $318(7.1)$ & 83.3 \\
\hline Renal & $99(2.2)$ & $47(1.1)$ & 23.4 & $52(1.2)$ & 86.5 \\
\hline VTE & $165(3.7)$ & $43(1.0)$ & 25.6 & $122(2.7)$ & 68.9 \\
\hline Respiratory & $120(2.7)$ & $88(2.0)$ & 18.2 & $32(0.7)$ & 81.3 \\
\hline Urinary tract infection & $381(8.6)$ & $51(1.3)$ & 20.7 & $323(7.3)$ & 72.1 \\
\hline Cardiac & $65(1.5)$ & $51(1.1)$ & 7.8 & $14(0.3)$ & 78.6 \\
\hline Death & $55(1.2)$ & $35(0.8)$ & - & $20(0.5)$ & 35.0 \\
\hline
\end{tabular}

Complications with counts less than 10 are excluded. VTE: venous thromboembolism. 


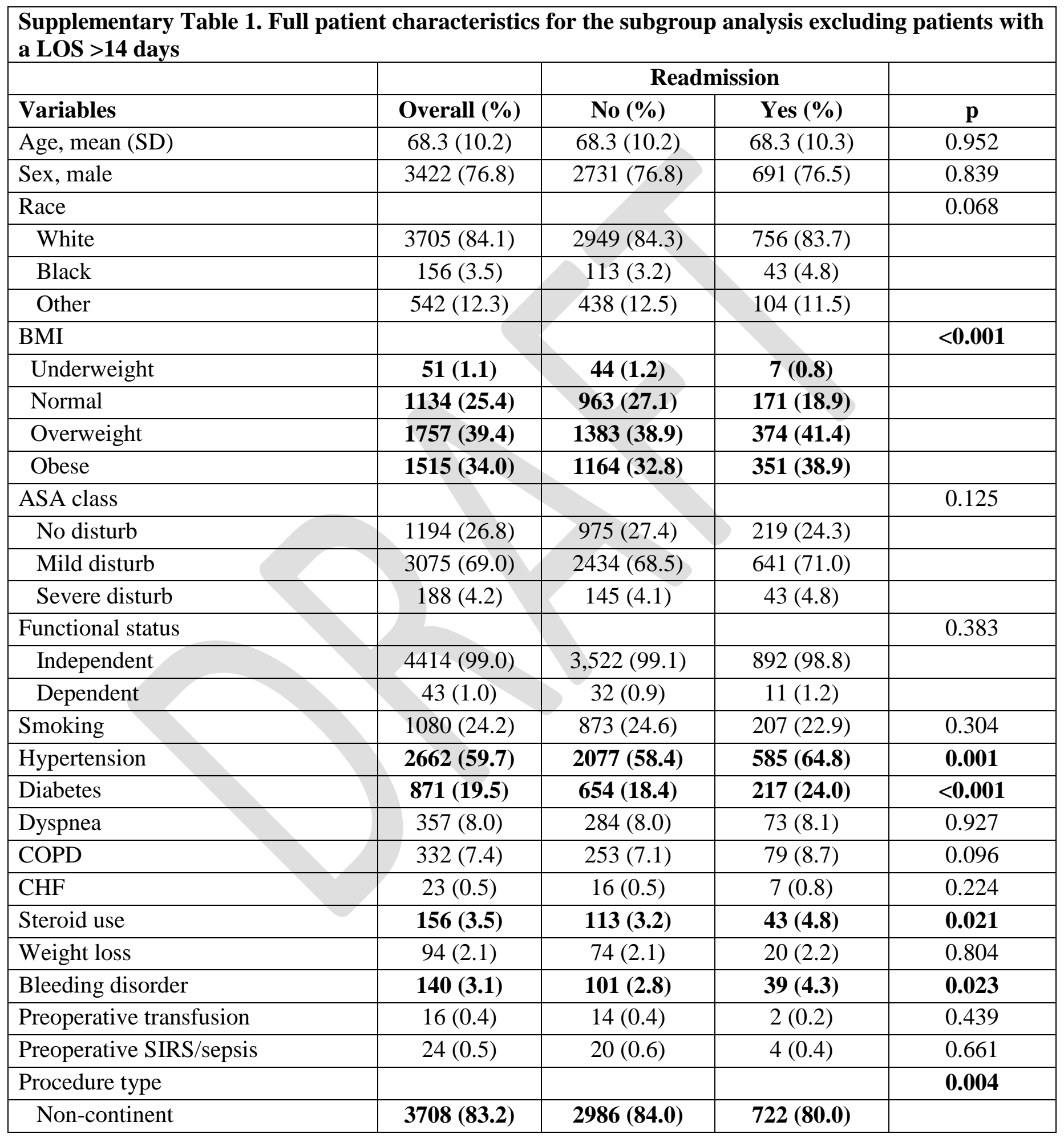




\begin{tabular}{|c|c|c|c|c|}
\hline Continent & 749 (16.8) & $568(16.0)$ & $181(20.0)$ & \\
\hline $\begin{array}{l}\text { Duration of operation (hours), mean } \\
\text { (SD) }\end{array}$ & $5.8(2.0)$ & $5.7(1.9)$ & $6.2(2.0)$ & $<0.001$ \\
\hline Length of stay (days), mean (SD) & $7.3(2.2)$ & $7.2(2.2)$ & $7.4(2.2)$ & 0.182 \\
\hline Wound classification & & & & 0.683 \\
\hline Clean & $69(1.6)$ & $58(1.6)$ & $11(1.2)$ & \\
\hline Clean/contaminated & $4154(93.2)$ & $3310(93.1)$ & $844(93.4)$ & \\
\hline Contaminated & 218 (4.9) & $172(4.8)$ & $46(5.1)$ & \\
\hline Dirty & $16(0.4)$ & $14(0.4)$ & $2(0.2)$ & \\
\hline Any complication & $1168(26.2)$ & 545 (15.3) & $623(69.0)$ & $<0.001$ \\
\hline Postoperative complication & $409(9.2)$ & $304(8.6)$ & 105 (11.6) & 0.004 \\
\hline Post-discharge complication & $838(18.8)$ & $266(7.5)$ & 572 (63.3) & $<0.001$ \\
\hline
\end{tabular}

Patients are stratified by readmission. ASA: American Society of Anesthesiologists; BMI: body mass index; CHF: congestive heart failure; COPD: chronic obstructive pulmonary disease; LOS: length of stay; SIRS: systemic inflammatory response syndrome; SD: standard deviation

\begin{tabular}{|c|c|c|c|c|}
\hline \multicolumn{5}{|c|}{ Supplementary Table 2. Full patient characteristics for the overall cohort stratified by readmission } \\
\hline \multirow[b]{2}{*}{ Variables } & \multirow{2}{*}{ Overall (\%) } & \multicolumn{2}{|c|}{ Readmission } & \multirow[b]{2}{*}{$\mathbf{P}$} \\
\hline & & No (\%) & Yes (\%) & \\
\hline Age, mean (SD) & $68.6(10.2)$ & $68.6(10.1)$ & $68.5(10.3)$ & 0.904 \\
\hline Sex, male & $3980(76.8)$ & 3228 (76.9) & $752(76.8)$ & 0.977 \\
\hline Race & 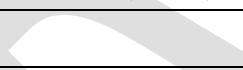 & +2 & & 0.081 \\
\hline White & 4235 (82.8) & 3424 (82.8) & $811(82.8)$ & \\
\hline Black & $194(3.8)$ & $146(3.5)$ & $48(4.9)$ & \\
\hline Other & $683(13.4)$ & 563 (13.6) & $120(12.3)$ & \\
\hline BMI & & & & $<0.001$ \\
\hline Underweight & $64(1.2)$ & $52(1.2)$ & $12(1.2)$ & \\
\hline Normal & $1307(25.2)$ & $1125(26.8)$ & $182(18.6)$ & \\
\hline Overweight & 2025 (39.1) & $1624(38.7)$ & $401(41.0)$ & \\
\hline Obese & $1783(34.4)$ & 1399 (33.3) & 384 (39.2) & \\
\hline ASA class & & & & 0.340 \\
\hline No disturb & 1355 (26.2) & 1117 (26.6) & $238(24.3)$ & \\
\hline Mild disturb & 3580 (69.1) & 2887 (68.7) & $693(70.8)$ & \\
\hline Severe disturb & $244(4.7)$ & $196(4.7)$ & $48(4.9)$ & \\
\hline Functional status & & & & 0.835 \\
\hline Independent & 5124 (98.9) & 4156 (99.0) & 968 (98.9) & \\
\hline
\end{tabular}




\begin{tabular}{|c|c|c|c|c|}
\hline Dependent & $55(1.1)$ & $44(1.0)$ & $11(1.1)$ & \\
\hline Smoking & $1244(24.0)$ & $1021(24.3)$ & $223(22.8)$ & 0.313 \\
\hline Hypertension & 3137 (60.6) & 2501 (59.5) & $636(65.0)$ & 0.002 \\
\hline Diabetes & $1032(19.9)$ & $797(19.0)$ & $235(24.0)$ & $<0.001$ \\
\hline Dyspnea & $444(8.6)$ & $358(8.5)$ & $86(8.8)$ & 0.793 \\
\hline COPD & 409 (7.9) & $320(7.6)$ & $89(9.1)$ & 0.124 \\
\hline CHF & $30(0.6)$ & $23(0.5)$ & $7(0.7)$ & 0.534 \\
\hline Steroid use & $183(3.5)$ & 137 (3.3) & $46(4.7)$ & 0.028 \\
\hline Weight loss & $117(2.3)$ & $91(2.2)$ & $26(2.7)$ & 0.354 \\
\hline Bleeding disorder & 174 (3.4) & $132(3.1)$ & $42(4.3)$ & 0.073 \\
\hline Preoperative transfusion & $19(0.4)$ & $17(0.4)$ & $2(0.2)$ & 0.350 \\
\hline Preoperative SIRS/sepsis & $33(0.6)$ & $29(0.7)$ & $4(0.4)$ & 0.318 \\
\hline Procedure type & & & & 0.023 \\
\hline Non-continent & $4301(83.1)$ & 3512 (83.6) & $789(80.6)$ & \\
\hline Continent & $878(17.0)$ & $688(16.4)$ & $190(19.4)$ & \\
\hline $\begin{array}{l}\text { Duration of operation (hours), mean } \\
\text { (SD) }\end{array}$ & $5.9(2.0)$ & $5.8(2.0)$ & $6.2(2.0)$ & $<0.001$ \\
\hline LOS (days), mean (SD) & $9.4(7.0)$ & $9.7(7.5)$ & $8.1(3.5)$ & $<0.001$ \\
\hline Wound classification & & 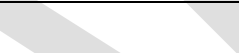 & & 0.504 \\
\hline Clean & $81(1.6)$ & $70(1.7)$ & $11(1.1)$ & \\
\hline Clean/contaminated & $4832(93.3)$ & 3915 (93.2) & $917(93.7)$ & \\
\hline Contaminated & $248(4.8)$ & $199(4.7)$ & $49(5.0)$ & \\
\hline 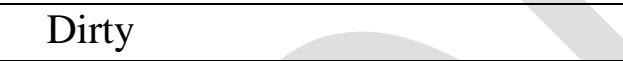 & $18(0.4)$ & $16(0.4)$ & $2(0.2)$ & \\
\hline Any complication & $1665(32.1)$ & $965(23.5)$ & 680 ( (69.5) & $<0.001$ \\
\hline Postoperative complication & 877 (16.9) & 731 (17.4) & $146(14.9)$ & 0.061 \\
\hline Post-discharge complication & 896 (17.3) & $292(7.0)$ & $604(61.7)$ & $<0.001$ \\
\hline
\end{tabular}

ASA: American Society of Anesthesiologists; BMI: body mass index; CHF: congestive heart failure; COPD: chronic obstructive pulmonary disease; LOS: length of stay; SIRS: systemic inflammatory response syndrome; SD: standard deviation. 


\begin{tabular}{|c|c|c|c|c|c|c|}
\hline \multicolumn{7}{|c|}{$\begin{array}{l}\text { Supplementary Table } 3 \text {. Multivariable regression for the subgroup analysis excluding patients with } \\
\text { LOS > } 14 \text { days of post-discharge complications, post-discharge major complications, and } \\
\text { readmission }\end{array}$} \\
\hline Covariates & \multicolumn{2}{|c|}{$\begin{array}{l}\text { Post-discharge } \\
\text { complications }\end{array}$} & \multicolumn{2}{|c|}{$\begin{array}{c}\text { Post-discharge major } \\
\text { complications }\end{array}$} & \multicolumn{2}{|c|}{ Readmission } \\
\hline & OR (95\% CI) & $\mathbf{p}$ & OR (95\% CI) & $\mathbf{p}$ & OR (95\% CI) & $\mathbf{p}$ \\
\hline Age & $1.00(0.99-1.01)$ & 0.882 & $1.01(0.99-1.02)$ & 0.307 & $1.01(1.00-1.01)$ & 0.065 \\
\hline \multicolumn{7}{|l|}{ Sex, male } \\
\hline Male & Reference & - & Reference & - & Reference & - \\
\hline Female & 1.07 (0.89-1.29) & 0.491 & $1.01(0.81-1.26)$ & 0.930 & $1.09(0.91-1.31)$ & 0.344 \\
\hline \multicolumn{7}{|l|}{ Race } \\
\hline White & Reference & - & Reference & - & Reference & - \\
\hline Black & $0.92(0.60-1.41)$ & 0.702 & $0.93(0.57-1.54)$ & 0.791 & $1.47(1.01-2.13)$ & 0.044 \\
\hline Other & $0.83(0.64-1.08)$ & 0.165 & 0.87 (0.64-1.19) & 0.388 & $1.09(0.86-1.38)$ & 0.492 \\
\hline \multicolumn{7}{|l|}{ BMI } \\
\hline Normal & Reference & - & Reference & - & Reference & - \\
\hline Underweight & $1.46(0.70-3.05)$ & 0.311 & $1.52(0.65-3.52)$ & 0.334 & $0.86(0.37-1.99)$ & 0.732 \\
\hline Overweight & $1.38(1.11-1.72)$ & 0.003 & $1.22(0.95-1.57)$ & 0.122 & $1.48(1.21-1.82)$ & $<0.001$ \\
\hline Obese & $1.73(1.39-2.17)$ & $<0.001$ & $1.60(1.23-2.07)$ & $<0.001$ & $1.51(1.21-1.87)$ & $<0.001$ \\
\hline \multicolumn{7}{|l|}{ ASA class } \\
\hline No disturb & Reference & - & Reference & - & Reference & - \\
\hline Mild disturb & $1.05(0.88-1.27)$ & 0.582 & $0.94(0.76-1.17)$ & 0.588 & $1.07(0.89-1.28)$ & 0.461 \\
\hline $\begin{array}{l}\text { Severe } \\
\text { disturb }\end{array}$ & $1.02(0.67-1.57)$ & 0.910 & $0.99(0.61-1.60)$ & 0.958 & $1.18(0.79-1.75)$ & 0.411 \\
\hline \multicolumn{7}{|l|}{$\begin{array}{l}\text { Functional } \\
\text { status }\end{array}$} \\
\hline Independent & Reference & - & Reference & - & Reference & - \\
\hline Dependent & $2.05(1.03-4.08)$ & 0.042 & $1.98(0.90-4.38)$ & 0.089 & $1.55(0.76-3.14)$ & 0.225 \\
\hline Smoking & $0.99(0.81-1.20)$ & 0.890 & $1.00(0.80-1.25)$ & 0.991 & $0.98(0.81-1.18)$ & 0.796 \\
\hline Hypertension & $1.15(0.96-1.35)$ & 0.120 & $1.27(1.04-1.56)$ & 0.021 & $1.15(0.97-1.36)$ & 0.102 \\
\hline Diabetes & $1.05(0.86-1.28)$ & 0.631 & $1.02(0.81-1.28)$ & 0.867 & $1.23(1.02-1.49)$ & 0.030 \\
\hline Dyspnea & $0.89(0.66-1.20)$ & 0.434 & $0.84(0.59-1.20)$ & 0.333 & $0.84(0.62-1.13)$ & 0.245 \\
\hline
\end{tabular}


Factors associated with readmission after radical cystectomy

\begin{tabular}{|c|c|c|c|c|c|c|}
\hline COPD & $1.40(1.03-1.89)$ & 0.030 & 1.39 (0.98-1.97) & 0.063 & $1.36(1.01-1.82)$ & 0.041 \\
\hline $\mathrm{CHF}$ & $1.02(0.37-2.83)$ & 0.975 & $1.15(0.37-3.52)$ & 0.811 & $1.25(0.49-3.16)$ & 0.638 \\
\hline Steroid use & $1.11(0.74-1.68)$ & 0.608 & $1.05(0.65-1.70)$ & 0.844 & $1.50(1.03-2.18)$ & 0.034 \\
\hline Weight loss & $1.53(0.93-2.52)$ & 0.092 & $1.03(0.55-1.95)$ & 0.915 & $1.17(0.70-1.96)$ & 0.548 \\
\hline $\begin{array}{l}\text { Bleeding } \\
\text { disorder }\end{array}$ & $1.15(0.76-1.75)$ & 0.515 & $1.25(0.78-2.00)$ & 0.361 & $1.43(0.97-2.11)$ & 0.069 \\
\hline $\begin{array}{l}\text { Preoperative } \\
\text { Transfusion }\end{array}$ & $1.27(0.35-4.59)$ & 0.713 & $0.58(0.07-4.45)$ & 0.599 & $0.59(0.13-2.69)$ & 0.494 \\
\hline $\begin{array}{l}\text { Preoperative } \\
\text { SIRS/sepsis }\end{array}$ & $1.16(0.42-3.21)$ & 0.773 & $1.54(0.51-4.67)$ & 0.443 & $0.77(0.25-2.34)$ & 0.644 \\
\hline \multicolumn{7}{|l|}{ Procedure type } \\
\hline $\begin{array}{l}\text { Non- } \\
\text { continent }\end{array}$ & Reference & - & Reference & & Reference & - \\
\hline Continent & 1.46 (1.18-1.79) & $<0.001$ & $1.47(1.16-1.86)$ & 0.002 & $1.35(1.10-1.66)$ & 0.004 \\
\hline $\begin{array}{l}\text { Duration of } \\
\text { operation } \\
\text { (hours) }\end{array}$ & $1.12(1.07-1.16)$ & $<0.001$ & $1.14(1.09-1.20)$ & $<0.001$ & $1.11(1.07-1.16)$ & $<0.001$ \\
\hline \multicolumn{7}{|l|}{$\begin{array}{l}\text { Wound } \\
\text { classification }\end{array}$} \\
\hline Clean & Reference & - & Reference & - & Reference & - \\
\hline $\begin{array}{l}\text { Clean } \\
\text { contaminated }\end{array}$ & $1.51(0.74-3.10)$ & 0.258 & $0.95(0.46-1.94)$ & 0.878 & $1.33(0.69-2.57)$ & 0.397 \\
\hline Contaminated & $0.91(0.40-2.05)$ & 0.821 & $0.58(0.25-1.35)$ & 0.206 & $1.29(0.62-2.69)$ & 0.499 \\
\hline Dirty & $0.81(0.15-4.29)$ & 0.803 & $0.76(0.14-4.09)$ & 0.749 & $0.57(0.11-2.99)$ & 0.509 \\
\hline LOS (days) & $1.00(0.96-1.04)$ & 0.877 & $0.99(0.91-1.70)$ & 0.652 & $0.99(0.96-1.03)$ & 0.669 \\
\hline $\begin{array}{l}\text { Postoperative } \\
\text { complication }\end{array}$ & $1.09(0.82-1.44)$ & 0.549 & $1.25(0.91-1.70)$ & 0.169 & $1.52(1.17-1.96)$ & 0.001 \\
\hline
\end{tabular}

ASA: American Society of Anesthesiologists; BMI: body mass index; CHF: congestive heart failure; CI: confidence interval; COPD: chronic obstructive pulmonary disease; LOS: length of stay; OR: odds ratio; SIRS: systemic inflammatory response syndrome; SD: standard deviation. 
Supplementary Table 4. Multivariable regression for the overall cohort of post-discharge complications, post-discharge major complications, and readmission

\begin{tabular}{|c|c|c|c|c|c|c|}
\hline \multirow[t]{2}{*}{ Covariates } & \multicolumn{2}{|l|}{$\begin{array}{l}\text { Post-discharge } \\
\text { complications }\end{array}$} & \multicolumn{2}{|c|}{$\begin{array}{l}\text { Post-discharge major } \\
\text { complications }\end{array}$} & \multicolumn{2}{|l|}{ Readmission } \\
\hline & OR (95\% CI) & $\mathbf{p}$ & OR (95\% CI) & $\mathbf{p}$ & OR (95\% CI) & $\mathbf{p}$ \\
\hline Age & $1.00(0.99-1.01)$ & 0.996 & $1.01(1.00-1.02)$ & 0.147 & $1.01(1.00-1.02)$ & 0.017 \\
\hline \multicolumn{7}{|l|}{ Sex, male } \\
\hline Male & Reference & - & Reference & - & Reference & - \\
\hline Female & $1.07(0.89-1.28)$ & 0.486 & $1.02(0.82-1.26)$ & 0.881 & $1.06(0.89-1.26)$ & 0.502 \\
\hline \multicolumn{7}{|l|}{ Race } \\
\hline White & Reference & - & Reference & - & Reference & - \\
\hline Black & $0.81(0.53-1.23)$ & 0.322 & $0.84(0.52-1.38)$ & 0.503 & 1.47 (1.04-2.09) & 0.029 \\
\hline Other & 0.89 (0.69-1.13) & 0.341 & $0.90(0.67-1.21)$ & 0.496 & $1.16(0.93-1.44)$ & 0.202 \\
\hline \multicolumn{7}{|l|}{ BMI } \\
\hline Normal & Reference & - & Reference & - & Reference & - \\
\hline Underweight & $1.72(0.88-3.39)$ & 0.113 & $1.72(0.78-3.78)$ & 0.180 & $1.55(0.79-3.04)$ & 0.198 \\
\hline Overweight & $1.40(1.13-1.72)$ & 0.002 & $1.24(0.97-1.58)$ & 0.092 & $1.50(1.23-1.83)$ & $<0.001$ \\
\hline Obese & $1.75(1.41-2.17)$ & $<0.001$ & $1.62(1.26-2.08)$ & $<0.001$ & $1.56(1.27-1.92)$ & $<0.001$ \\
\hline \multicolumn{7}{|l|}{ ASA class } \\
\hline No disturb & Reference & - & Reference & - & Reference & - \\
\hline Mild disturb & $1.02(0.86-1.22)$ & 0.809 & $0.91(0.74-1.12)$ & 0.393 & $1.05(0.89-1.25)$ & 0.564 \\
\hline $\begin{array}{l}\text { Severe } \\
\text { disturb }\end{array}$ & $1.12(0.76-1.67)$ & 0.556 & $1.02(0.64-1.60)$ & 0.943 & $1.14(0.79-1.66)$ & 0.475 \\
\hline \multicolumn{7}{|l|}{$\begin{array}{l}\text { Functional } \\
\text { status }\end{array}$} \\
\hline Independent & Reference & - & Reference & - & Reference & - \\
\hline Dependent & $1.97(1.02-3.80)$ & 0.042 & $1.80(0.82-3.92)$ & 0.140 & $1.30(0.65-2.59)$ & 0.457 \\
\hline Smoking & $0.99(0.82-1.19)$ & 0.874 & $1.00(0.80-1.25)$ & 0.973 & 0.97 (0.81-1.16) & 0.739 \\
\hline
\end{tabular}


Factors associated with readmission after radical cystectomy

\begin{tabular}{|c|c|c|c|c|c|c|}
\hline Hypertension & $1.13(0.96-1.34)$ & 0.137 & $1.25(1.03-1.52)$ & 0.026 & $1.11(0.95-1.31)$ & 0.196 \\
\hline Diabetes & $1.03(0.85-1.25)$ & 0.736 & $1.00(0.80-1.25)$ & 0.978 & $1.22(1.02-1.45)$ & 0.032 \\
\hline Dyspnea & $1.01(0.76-1.34)$ & 0.940 & $0.87(0.62-1.22)$ & 0.415 & $0.89(0.67-1.16)$ & 0.381 \\
\hline COPD & $1.41(1.06-1.88)$ & 0.018 & $1.37(0.98-1.92)$ & 0.064 & $1.38(1.04-1.81)$ & 0.023 \\
\hline $\mathrm{CHF}$ & $0.79(0.29-2.12)$ & 0.632 & $0.99(0.33-2.94)$ & 0.981 & $0.98(0.41-2.36)$ & 0.967 \\
\hline Steroid use & $1.16(0.79-1.72)$ & 0.447 & $1.13(0.71-1.80)$ & 0.597 & $1.48(1.04-2.11)$ & 0.031 \\
\hline Weight loss & $1.56(0.97-2.49)$ & 0.065 & $1.09(0.60-2.00)$ & 0.770 & $1.48(0.93-2.34)$ & 0.098 \\
\hline $\begin{array}{l}\text { Bleeding } \\
\text { disorder }\end{array}$ & $1.15(0.77-1.72)$ & 0.482 & $1.19(0.75-1.89)$ & 0.449 & $1.35(0.93-1.94)$ & 0.110 \\
\hline $\begin{array}{l}\text { Preoperative } \\
\text { transfusion }\end{array}$ & $1.14(0.32-4.09)$ & 0.826 & $0.53(0.07-4.05)$ & 0.540 & $0.52(0.12-2.32)$ & 0.391 \\
\hline $\begin{array}{l}\text { Pre-operative } \\
\text { SIRS/sepsis }\end{array}$ & $0.90(0.33-2.43)$ & 0.834 & $1.25(0.42-3.69)$ & 0.689 & $0.60(0.20-1.78)$ & 0.358 \\
\hline \multicolumn{7}{|l|}{ Procedure type } \\
\hline $\begin{array}{l}\text { Non- } \\
\text { continent }\end{array}$ & Reference & - & Reference & - & Reference & - \\
\hline Continent & $1.44(1.18-1.75)$ & $<0.001$ & $1.46(1.16-1.84)$ & 0.001 & $1.30(1.07-1.58)$ & 0.009 \\
\hline $\begin{array}{l}\text { Duration of } \\
\text { operation } \\
\text { (hours) }\end{array}$ & $1.11(1.07-1.16)$ & $<0.001$ & $1.14(1.09-1.19)$ & $<0.001$ & $1.11(1.07-1.15)$ & $<0.001$ \\
\hline \multicolumn{7}{|l|}{$\begin{array}{l}\text { Wound } \\
\text { classification }\end{array}$} \\
\hline Clean & Reference & - & Reference & - & Reference & - \\
\hline $\begin{array}{l}\text { Clean } \\
\text { contaminated }\end{array}$ & $1.70(0.83-3.44)$ & 0.144 & $1.04(0.51-2.12)$ & 0.914 & $1.50(0.78-2.87)$ & 0.221 \\
\hline Contaminated & $1.01(0.45-2.25)$ & 0.987 & $0.65(0.28-1.52)$ & 0.320 & $1.46(0.71-3.01)$ & 0.301 \\
\hline Dirty & $1.02(0.20-5.35)$ & 0.977 & $0.95(0.18-5.04)$ & 0.956 & $0.73(0.14-3.73)$ & 0.708 \\
\hline LOS (days) & $0.94(0.92-0.96)$ & $<0.001$ & $0.93(0.90-0.95)$ & $<0.001$ & $0.93(0.91-0.95)$ & $<0.001$ \\
\hline $\begin{array}{l}\text { Postoperative } \\
\text { complication }\end{array}$ & $0.99(0.76-1.28)$ & 0.933 & $1.15(0.86-1.55)$ & 0.353 & $1.39(1.10-1.76)$ & 0.005 \\
\hline
\end{tabular}

ASA: American Society of Anesthesiologists; BMI: body mass index; CHF: congestive heart failure; CI: confidence interval; COPD: chronic obstructive pulmonary disease; LOS: length of stay; OR: odds ratio; SIRS: systemic inflammatory response syndrome; SD: standard deviation. 


\begin{tabular}{|c|c|c|c|c|c|}
\hline \multicolumn{6}{|c|}{$\begin{array}{l}\text { Supplementary Table } 5 \text {. Timing of specific postoperative complications in the overall cohort and their } \\
\text { associated readmission rates }\end{array}$} \\
\hline Complication type & $\begin{array}{c}\text { Overall } \\
(\%)\end{array}$ & $\begin{array}{c}\text { Number } \\
\text { occurring } \\
\text { postoperative, } \\
\text { n (\%) }\end{array}$ & $\begin{array}{c}\text { Readmission } \\
\text { rate when } \\
\text { postoperative }\end{array}$ & $\begin{array}{c}\text { Number } \\
\text { occurring post- } \\
\text { discharge, } n(\%)\end{array}$ & $\begin{array}{l}\text { Readmission } \\
\text { rate when post- } \\
\text { discharge }\end{array}$ \\
\hline Major complications & $1213(23.4)$ & $655(12.7)$ & 13.6 & $604(11.7)$ & 79.0 \\
\hline Minor complications & $989(19.1)$ & $452(8.7)$ & 16.8 & $567(11.0)$ & 62.8 \\
\hline Wound & 755 (14.6) & 397 (7.7) & 16.6 & $380(7.3)$ & 61.8 \\
\hline Sepsis & 597 (11.5) & $263(5.1)$ & 5.3 & $335(6.5)$ & 83.0 \\
\hline Renal & $168(3.2)$ & $114(2.2)$ & 12.3 & $54(1.0)$ & 87.0 \\
\hline VTE & 237 (4.6) & $111(2.1)$ & 14.4 & $126(2.4)$ & 66.7 \\
\hline Respiratory & $259(5.0)$ & $223(4.3)$ & 9.0 & $36(0.7)$ & 83.3 \\
\hline Urinary tract infection & $481(9.3)$ & $143(2.8)$ & 12.6 & $338(6.5)$ & 71.9 \\
\hline Cardiac & $105(2.0)$ & $91(1.8)$ & 11.0 & $14(0.3)$ & 78.6 \\
\hline Death & $83(1.6)$ & $62(1.2)$ & - & $21(0.4)$ & 33.3 \\
\hline
\end{tabular}

VTE: venous thromboembolism. 
